\title{
Hydrogel Nanofibers from Carboxymethyl Sago Pulp and Its Controlled Release Studies as a Methylene Blue Drug Carrier
}

\author{
Nafeesa Mohd Kanafi ${ }^{1}$, Norizah Abdul Rahman ${ }^{1,2, *(D)}$, Nurul Husna Rosdi ${ }^{1}$, Hasliza Bahruji ${ }^{3}$ \\ and Hasmerya Maarof ${ }^{4}$ \\ 1 Department of Chemistry, Faculty of Science, Universiti Putra Malaysia, 43400 UPM Serdang, Malaysia; \\ nafeesakanafi@yahoo.com (N.M.K.); nurulhusnarosdi73@gmail.com (N.H.R.) \\ 2 Laboratory of Materials Processing and Technology, Institute of Advanced Technology, Universiti Putra \\ Malaysia, 43400 UPM Serdang, Malaysia \\ 3 Centre of Advanced Material and Energy Science, University Brunei Darussalam, Jalan Tungku Link, \\ BE 1410, Brunei Darussalam; hasliza.bahruji@ubd.edu.bn \\ 4 Department of Chemistry, Faculty of Science, Universiti Teknologi Malaysia, 81310 UTM Johor Bahru, \\ Malaysia; hasmerya@kimia.fs.utm.my \\ * Correspondence: a_norizah@upm.edu.my
}

Received: 12 May 2019; Accepted: 3 June 2019; Published: 15 June 2019

\begin{abstract}
The potential use of carboxymethyl sago pulp (CMSP) extracted from sago waste for producing hydrogel nanofibers was investigated as a methylene blue drug carrier. Sago pulp was chemically modified via carboxymethylation reaction to form carboxymethyl sago pulp (CMSP) and subsequently used to produce nanofibers using the electrospinning method with the addition of poly(ethylene oxide) (PEO). The CMSP nanofibers were further treated with citric acid to form cross-linked hydrogel. Studies on the percentage of swelling following the variation of citric acid concentrations and curing temperature showed that $89.20 \pm 0.42 \%$ of methylene blue (MB) was loaded onto CMSP hydrogel nanofibers with the percentage of swelling $4366 \pm 975 \%$. Meanwhile, methylene blue controlled release studies revealed that the diffusion of methylene blue was influenced by the $\mathrm{pH}$ of buffer solution with $19.44 \%$ of $\mathrm{MB}$ released at $\mathrm{pH} 7.34$ within $48 \mathrm{~h}$ indicating the potential of CMSP hydrogel nanofibers to be used as a drug carrier for MB.
\end{abstract}

Keywords: carboxymethyl sago pulp; controlled release; electrospinning; hydrogel; nanofiber

\section{Introduction}

Sago palm (Metroxylon sago) is largely grown in tropical lowland forest and swamp areas. Sarawak, Malaysia is recognized as the largest sago-growing area with an estimated 54,000 hectares in 2013 [1,2]. Sago starch is the main product of sago palm, widely exported to the Peninsular Malaysia, Japan, Singapore and other countries with a total amount of 48,000 tons in 2013 [3]. The extraction of sago starch involves removing the bark of sago palm followed by rasping and sieving of the stem to produce starch slurry. The resulting slurry is then put to further settling, washing and drying processes to produce purified starch. The process also produces a fibrous sago waste by-product, with approximately 7 tons of production from a daily single processing mill [2]. Sago waste is a light brown lignocellulosic biomass comprising cellulose, hemicellulose and lignin. During the pre-treatment process, which is bleaching, hemicellulose and lignin are solubilized and degraded, thus resulting in sago pulp rich in cellulose [1,4]. Cellulose is a long and linear polysaccharide polymer that consists of glucose units that linked via beta 1,4-glycosidic bond. Studies on the production of functionalized cellulose derivatives, 
such as carboxymethylcellulose [2], hydroxypropyl methylcellulose (HPMC) and methylcellulose [5] have revealed their potential use as a drug carrier in pharmaceutical industries [2,4].

Hydrogel is often produced using chemical or physical cross-linking methods to form a three-dimensional polymeric structure capable of retaining water or biological fluid beyond its dry weight without dissolution in water [6-8]. The ionic groups within the hydrogel structure respond towards external changes such as $\mathrm{pH}$, ionic strength and temperature which consequently influence the uptake and release of fluid [9]. It has been extensively studied as an excellent material for biomedical applications due to its softness, super-absorbency, biodegradability, biocompatibility, hydrophilicity and similarity with extracellular matrix (ECM) [10]. As the hydrogel structure can simulate the ECM, it has been widely applied in drug delivery and wound dressing from various synthetic and natural materials [11,12]. Furthermore, hydrogel has a low chance of triggering negative immune responses in the human body as it has a low interfacial tension with biological fluids that reduce cell adhesion. Among the various types of stimuli responsive hydrogels, $\mathrm{pH}$ sensitive hydrogels are the most studied, especially in drug delivery and wound dressing applications [10].

Carboxymethyl sago pulp (CMSP) is also known as carboxymetyl cellulose. It is a functionalized sago pulp with the presence of carboxymethyl groups bound to the cellulose backbone. The hydroxyl groups bound to carboxymethyl groups are responsible for its adsorption behavior [13]. The preparation of carboxymethylated cellulose from various agricultural-by-products through the carboxymethylation process in alkaline conditions has been well documented in the literature [2,13-17]. CMSP hydrogel is sensitive towards the environment and tends to adsorb a large amount of fluid in various $\mathrm{pH}$ media, leading to swelling on its structure [18]. The swelling of CMSP hydrogel reported by Pushpamalar et al. showed that the hydrogel has a high swelling ratio at $\mathrm{pH} 7$ [18]. Furthermore, CMSP hydrogel in the form of microdiscs and microbeads loaded with ciprofloxacin and 5-aminosalicylic acid showed its potential application as a drug carrier due to its ability to release a drug at different $\mathrm{pH}[19,20]$.

Designing of nanomaterials with low density, large surface area, high pore volume and tight pore size has been the main focus of research in biomedical fields [21,22]. Electrospinning is a highly versatile method for producing nanofibers using natural or synthetic polymers, which can be used in drug and therapeutic agent deliveries, wound dressings and in the tissue engineering field $[11,22,23]$. In recent years, many studies on nanofibrous cellulose derivatives, including cellulose acetate nanofibers, have been applied in various applications, including biomedical [24]. In thist study, the production of CMSP hydrogel nanofibers from sago waste was investigated for controlled drug release applications. The CMSP nanofibers were prepared by incorporation with poly(ethylene oxide) (PEO) via an electrospinning technique with relatively low voltage used $(20 \mathrm{kV})$ compared to electrospun carboxymethyl cellulose (CMC)/PEO fibers as reported previously $[5,25]$. To the best of the authors' knowledge, no study has been performed for CMSP/PEO nanofibers fabricated using electrospinning techniques followed by treatment with citric acid, a cross-linker to form hydrogel. As an electro-spinnable and biocompatible polymer, PEO was blended with CMSP to facilitate the formation of nanofibers. The controlled release of methylene blue (MB) from CMSP hydrogel nanofibers was investigated at different $\mathrm{pH}$ solutions. $\mathrm{MB}$ acts as a drug model with many uses in clinical medicine including antimalarial agents, in the treatment of early Alzheimer's and methemoglobinemia [26-28]. Furthermore, $\mathrm{MB}$ is commonly used as preliminary test for hydrogel-controlled release and adsorption studies [29-31].

\section{Materials and Methods}

\subsection{Materials}

The CMSP (DS = 0.6) from sago waste was prepared based on the method reported by Pushpamalar et al. (2006) [2]. Poly(ethylene oxide) (PEO), citric acid and sodium monochloroacetate were purchased from Sigma Aldrich (St. Louis, MO, USA). Sodium hydroxide was bought from Bio Basic Canada Inc. (Markham, ON, Canada). Isopropanol, methanol and nitric acid were purchased from J. Kollin 
Chemicals (UK), while glacial acetic acid was purchased from J.T. Baker (Phillipsburg, NJ, USA). Methylene blue was obtained from Friendemann Schmidt (Parkwood, WA, USA) and distilled water was used throughout the study. All chemicals were used without further purification.

\subsection{Carboxymethylation of Sago Pulp}

To start with, $10.0 \mathrm{~g}$ of dried ground sago pulp was added into the dissolution tester followed by the addition of $200 \mathrm{~mL}$ of isopropanol with continuous stirring at $60 \mathrm{rpm}$ for $30 \mathrm{~min}$. Then, $20 \mathrm{~mL}$ of $25 \%(\mathrm{wt} / \mathrm{vol})$ sodium hydroxide solution was added drop-wise into the mixture and stirred for an hour at room temperature. Following this, $12.0 \mathrm{~g}$ of sodium monochloroacetate was added into the reaction mixture for carboxymethylation reaction and the speed of the stirrer was increased to $100 \mathrm{rpm}$. The resulting mixture was stirred for another $30 \mathrm{~min}$ and heated at $45^{\circ} \mathrm{C}$ for $3 \mathrm{~h}$ with continuous stirring. The mixture was cooled to room temperature and filtered to obtained carboxymethyl sago pulp (CMSP) residue. The residue was thoroughly washed with $100 \%$ methanol and treated with glacial acetic acid before drying to form CMSP powder. The degree of substitutions (DS) of the prepared CMSP was determined by potentiometric back titration [2]. Firstly, CMSP was treated using nitric acid. Then, $0.5 \mathrm{~g}$ of acid CMSP was weighed into the Erlenmeyer flask followed by the addition of $100 \mathrm{~mL}$ of distilled water and stirred. Subsequently, $25 \mathrm{~mL}$ of $0.5 \mathrm{M}$ sodium hydroxide was added, stirred and the solution was boiled for approximately $15 \mathrm{~min}$ until dissolved. Finally, 1 drop of phenolphthalein as an indicator was added into the heated solution and titrated with $0.3 \mathrm{~N}$ of hydrochloric acid.

\subsection{Preparation of CMSP/PEO Hydrogel Nanofibers}

The CMSP nanofibers were prepared using the electrospinning method. PEO was added to CMSP to facilitate the formation of nanofibers. The CMSP/PEO solution was prepared by dissolving the CMSP/PEO in water. CMSP and PEO were weighed at various ratios of CMSP to PEO prior to dissolution in water. The mixture was stirred in a beaker at room temperature to form homogenous solution. The CMSP/PEO solution was filled in a $5 \mathrm{~mL}$ syringe fitted with a metal needle for the electrospinning process. The applied voltage and the tip-to-collector distance were kept at $20 \mathrm{kV}$ and $15 \mathrm{~cm}$, respectively. The parameters used to optimize CMSP nanofibers production were varied with (a) the ratio of CMSP to PEO in the range of 1:0, 3:1, 1:1 and 1:3; (b) the concentration of CMSP/PEO solution from $4 \%, 6 \%, 8 \%$ and $10 \%(\mathrm{wt} / \mathrm{vol} \%)$, and (c) the flow rate of CMSP/PEO solution during the electrospinning at $0.6 \mathrm{~mL} / \mathrm{h}, 0.8 \mathrm{~mL} / \mathrm{h}, 1.0 \mathrm{~mL} / \mathrm{h}$ and $1.2 \mathrm{~mL} / \mathrm{h}$. The electrospinning process was conducted at room temperature with a horizontal setup while humidity was kept below $60 \%$ using silica gel to reduce humidity in the electrospinning box. The optimized electrospinning conditions were used to prepare CMSP nanofibers for preparing hydrogel nanofibers. The effects of citric acid concentration and the curing temperature for production of CMSP hydrogel nanofibers were investigated with percentage of citric acid varied at $23 \%, 29 \%, 33 \%$ and $38 \%$, as well as curing temperatures at $60{ }^{\circ} \mathrm{C}$, $70{ }^{\circ} \mathrm{C}, 80^{\circ} \mathrm{C}$ and $90^{\circ} \mathrm{C}$. The curing period was kept constant at $450 \mathrm{~min}$.

\subsection{Swelling Studies of CMSP Hydrogel Nanofiber}

The swelling studies were carried out on the optimized hydrogel nanofibers. The cross-linked dry nanofibers were weighed $(W d)$ before immersion in $15 \mathrm{~mL}$ of distilled water for $24 \mathrm{~h}$. The weight of nanofibers hydrogel (Ws) was measured following $24 \mathrm{~h}$ immersion and the percentage of swelling was calculated according to Equation (1) [8,32]. The experiments were carried out in triplicate to obtain an average value. The balance used was Mettler Toledo with 4 decimal points. Later, the swelled optimized hydrogel nanofibers were dried in an oven overnight to constant weight at $50{ }^{\circ} \mathrm{C}$ before drug loading.

$$
Q(\%)=\frac{W s-W d}{W d} \times 100
$$

where $Q=$ percentage of swelling, $W s=$ weight of nanofibers hydrogel, $W d=$ weight of the initial nanofibers. 


\subsection{Drug Controlled Release Studies}

Methylene blue (MB) was loaded into dried hydrogel nanofibers by immersion in $100 \mathrm{ppm}$ of methylene blue solution in a petri dish for $24 \mathrm{~h}$. The petri dish was covered with aluminum foil to prevent degradation of MB with light. After $24 \mathrm{~h}$, the MB-loaded hydrogel was washed with distilled water and excess MB solution on the surface of the hydrogel was removed using filter paper. The efficiency of methylene blue entrapment was determined by analyzing the concentration of MB before and after immersion with nanofibers. Concentration of methylene blue was determined using UV-vis spectrophotometer (Shimadzu, Kyoto, Japan). Meanwhile, the MB entrapment efficiency was calculated based on Equation (2) [33,34]:

$$
\begin{aligned}
& \text { Entrapement ef ficiency }(E E)(\%) \\
& \qquad=\frac{(\text { total initial concentration of } \mathrm{MB}-\text { free } \mathrm{MB} \text { concentration })}{\text { total initial concentration of } \mathrm{MB}} \times 100
\end{aligned}
$$

In controlled release studies, MB-loaded hydrogel was immersed in phosphate-buffer saline (PBS) with pH 7.34 at room temperature for $48 \mathrm{~h}$. Further, $3 \mathrm{~mL}$ aliquot was withdrawn periodically and similar volumes of fresh PBS solution was replaced. The collected samples were measured by determining the absorption of light at $664 \mathrm{~nm}$ using a UV-vis spectrophotometer. The procedures were repeated at $\mathrm{pH} 1.02,4.0$ and 8.0 of buffer solutions. The cumulative percentage of MB release was calculated based on Equation (3) [35]:

$$
\begin{aligned}
& \text { Cumulative percentage release (\%) } \\
& =\frac{\text { vol. of sample withdrawn }(m l)}{\text { bath volume }(m l)} \times P(t-1)+P t
\end{aligned}
$$

where

$P t=$ Percentage release at time $t$ (minutes)

$P(t-1)=$ Percentage release previous to ' $t$ '

\subsection{Fourier Transform Infrared (FTIR) Spectroscopy}

Fourier transform infrared (FTIR) spectroscopy was used to characterize the presence of functional groups in the pre-treated sago pulp and CMSP. FTIR spectra of the materials were obtained using Perkin Elmer Spectrum 100 Fourier Transform Infrared Spectrophotometer (Perkin Elmer, Selton, CT, USA). Scanning was carried out in the range $4000-280 \mathrm{~cm}^{-1}$. Attenuated Total Reflection (ATR) [6] was utilized as the sampling technique.

\subsection{Ultraviolet-Visible (UV-Vis) Spectrophotometer}

A UV-visible (UV-vis) spectrophotometer was used to determine the concentration of MB. Ultraviolet measurements were performed using Shimadzu UV-visible spectrophotometer (Shimadzu, Kyoto, Japan). The wavelength number range to detect the absorption was set at $400-800 \mathrm{~nm}$ and the $\mathrm{MB} \lambda_{\max }=664 \mathrm{~nm}$.

\subsection{Scanning Electron Microscopy (SEM)}

Scanning electron microscopy was used to determine surface morphology of nanofibers produced using the electrospinning method and hydrogel nanofibers following the immersion in water and MB solution. For swelling nanofibers, the samples were freeze-dried before SEM analysis. All the nanofibers were observed using the scanning electron microscopy (SEM) model JEOL JSM 6400 (JEOL, Tokyo, Japan) attached with energy-dispersive X-ray (EDX). The samples were sputter coated with a thin layer of gold before being observed under the SEM at a voltage of $15 \mathrm{kV}$. More than 100 of the nanofibers were randomly measured from SEM images by using the image J program (Version 1.52o, SpartanCoders, Softonic International S.A.) to measure the mean diameter of the fibers. 


\section{Results and Discussion}

\subsection{Fourier Transform Infrared Spectroscopy Studies}

Infrared analysis was carried out on the pre-treated sago pulp and CMSP as shown in Figure 1. The pre-treated sago pulp showed a broad O-H stretching vibration band at $3600-3000 \mathrm{~cm}^{-1}$ accompanied with the $\mathrm{OH}$ bending vibration of the absorbed water band at $1623 \mathrm{~cm}^{-1}$ [36]. However, in CMSP, the intensity of the $\mathrm{O}-\mathrm{H}$ stretching vibration was reduced with the $\mathrm{OH}$ bending vibration band shifts toward lower wavenumber at $1596 \mathrm{~cm}^{-1}$. The shift of the peak is associated with the COO stretching vibration in CMSP. The features provide evidence on the substitution of $\mathrm{OH}$ with the carboxymethyl group in CMSP following the carboxymethylation reaction. The CMSP also demonstrated a strong absorbance band at $1400 \mathrm{~cm}^{-1}$ in comparison to sago pulp which corresponded to the $-\mathrm{CH}_{2}$ scissoring vibration. The sago pulp and CMSP also revealed absorbance bands at $1030-1020 \mathrm{~cm}^{-1}$ which corresponded to the $-\mathrm{CH}-\mathrm{O}-\mathrm{CH}_{2}$ stretching vibration of the ether group [17]. In sago pulp, the ether group originated from the linkage of $1,4-\beta$-D-glucoside group $(>\mathrm{CH}-\mathrm{O}-\mathrm{CH}<)$ in the cellulose molecule. In CMSP however, the absorbance band of ether also originated from the ether group of the carboxymethylation of sago pulp, in which the two types of ether were overlapped in the CMSP $[2,17,18]$.

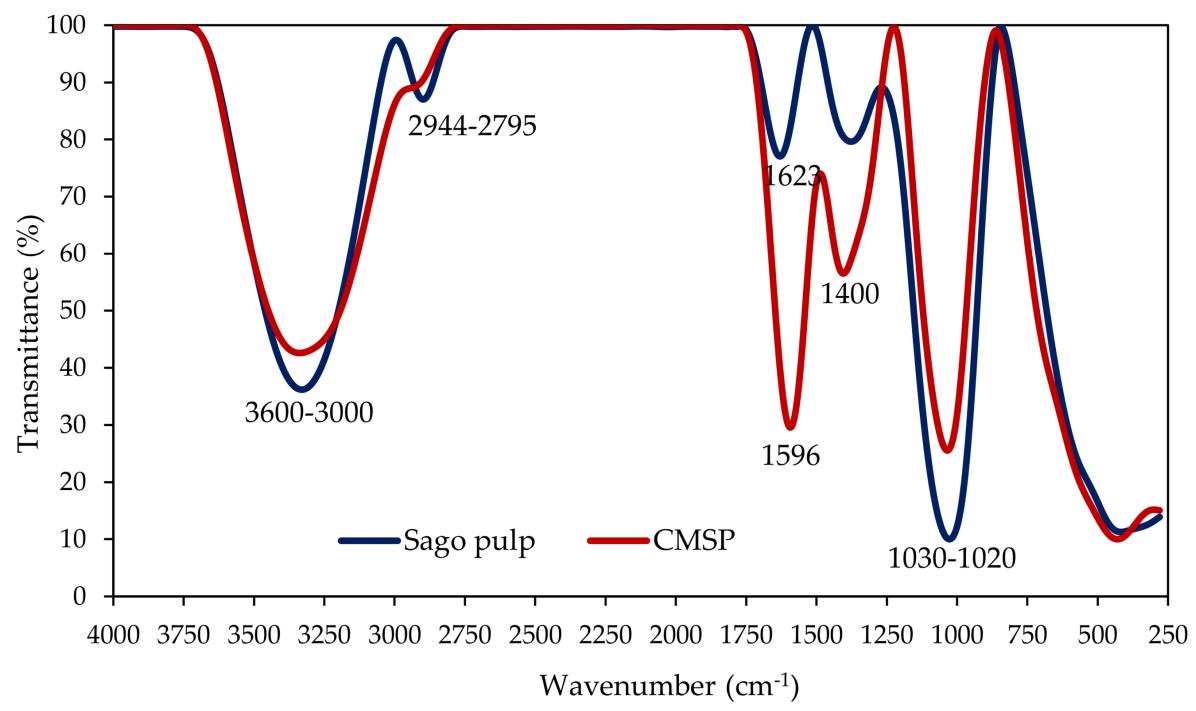

Figure 1. Fourier transform infrared (FTIR) spectra pattern of pre-treated sago pulp and carboxymethyl sago pulp (CMSP).

\subsection{Optimization of Electrospinning Parameters of CMSP Nanofibers}

Optimization of the electrospinning parameters was carried out by varying the weight ratio of CMSP to PEO, the concentration of CMSP/PEO solutions and the CMSP/PEO solution flow rates. The applied voltage was fixed at $20 \mathrm{kV}$ while the tip-to-collector distance was fixed at $15 \mathrm{~cm}$. The electrospinning process was conducted at room temperature while the humidity was kept below $60 \%$.

\subsubsection{Effects of Weight Ratio of CMSP to PEO}

CMSP is a natural polymer that requires synthetic polymer to assist the electrospinning process. In this study, CMSP was mixed with a biocompatible polymer, PEO, to facilitate the electrospinning process by increasing the elasticity of the CMSP solution [37]. Figure 2 shows the morphology and the average diameter of nanofibers at three different weight ratios of CMSP to PEO. The morphology of the resulting fibers had gradually transformed from microbeads to uniform fiber structure following the variation of CMSP to PEO ratios from 3:1 to 1:3. There was no SEM image to study the morphology of ratio 1CMSP:0PEO because CMSP cannot be electrospun alone. It needs to be blended with electro-spinnable polymer, PEO, to allow CMSP to be electrospun into nanofibers. In the presence 
of high CMSP content as in 3CMSP:1PEO ratio, the electrospinning process produced a microbead structure with only a few nanofibers as observed from the SEM analysis. At equal ratio of CMSP and $\mathrm{PEO}$, the electrospinning of the mixtures produced nanofibers with wide fiber diameter distribution between 100-1000 nm. However, the presence of microbead structures was still visible from SEM images. At 1CMSP:3PEO ratio, the formation of nanofibers with narrow diameter distribution were observed with average fiber diameter in the range of $51-250 \mathrm{~nm}$. The optimization of the electrospinning process continued using the CMSP:PEO ratios of 1:1 and 1:3, due to significantly less microbead structures produced.
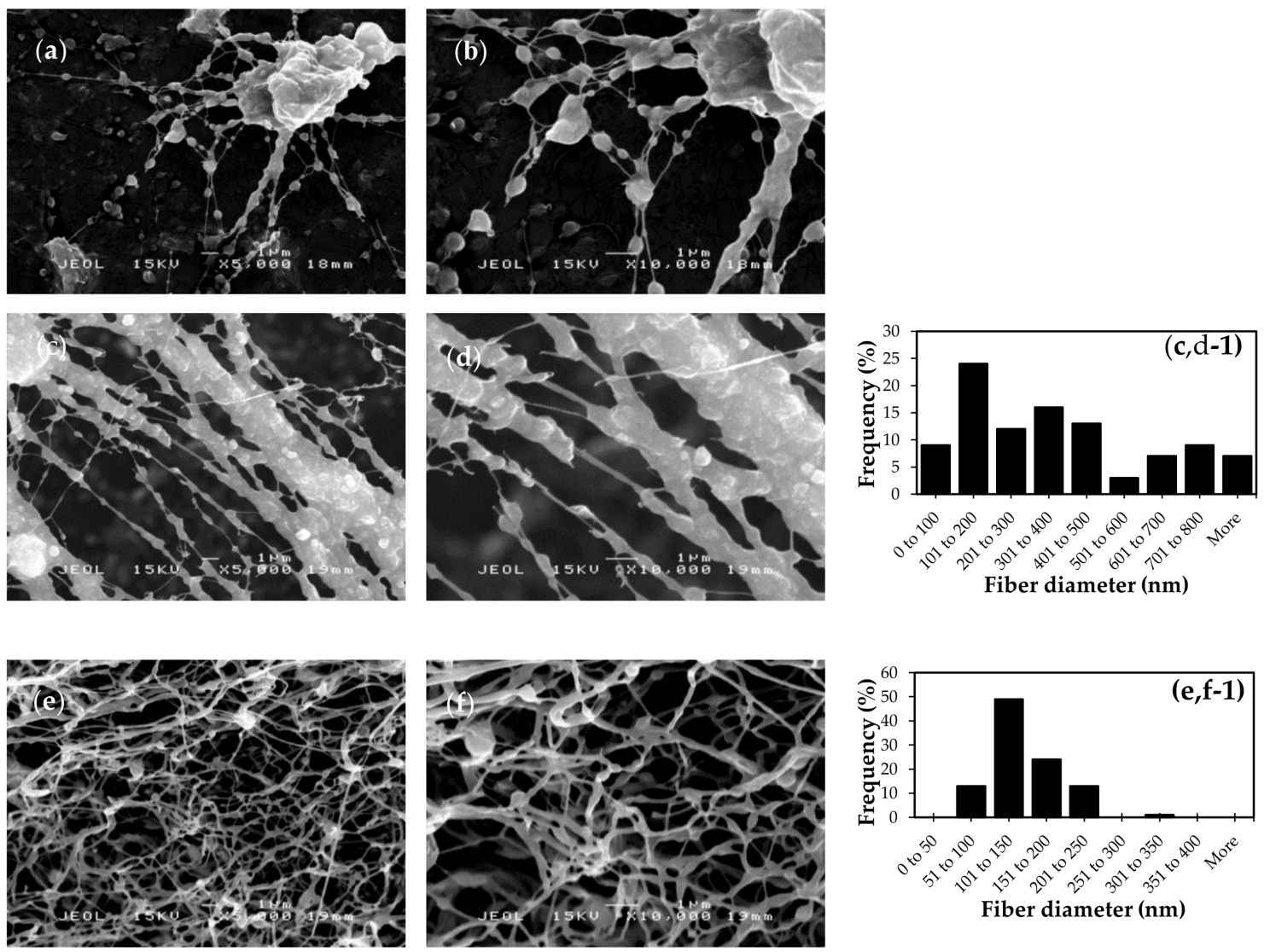

Figure 2. SEM images (a-f) and the corresponding fiber diameter distribution $((\mathbf{c}, \mathbf{d}-\mathbf{1})-(\mathbf{e}, \mathbf{f}-\mathbf{1}))$ of CMSP nanofibers at variation of CMSP to poly(ethylene oxide) (PEO) weight ratios (a,b) 3:1, (c,d) 1:1 and (e,f) 1:3 at fixed $6 \%$ solution concentration, $20 \mathrm{kV}$ applied voltage, $15 \mathrm{~cm}$ of tip-to-collector distance and $0.8 \mathrm{~mL} / \mathrm{h}$ of flow rate.

\subsubsection{Effects of Concentration of CMSP/PEO Solution}

The morphology of nanofibers is significantly affected by the concentration of polymer solution during the electrospinning process [38,39]. In this study, electrospinning was carried out at four different concentrations of CMSP/PEO solutions $~ 4 \%, 6 \%, 8 \%$ and $10 \%(\mathrm{wt} / \mathrm{vol} \%)$ with the ratio of CMSP to PEO kept at 1:1 and 1:3. SEM images shown in Figure 3 reveal the concentration of solution that significantly affected the formation of nanofibers. At $4 \%$ of solution concentration, the presence of microbead structures was observed together with the nanofibers, with average diameter ranging from 100-200 nm. Increasing the concentration had improved the formation of nanofibers with the absence of microbead structures. At 10\% concentration, nanofibers obtained at 1:3 and 1:1 ratios showed uniform nanofibers morphology with no visible formation of microbeads. High concentration of polymer in the electrospinning jet significantly enhanced the interaction between polymer chains in solution, which led to a greater resistance of the solution against the pulling force by electrical charges [40]. Nanofibers 
with narrow mean diameter of $214 \pm 62 \mathrm{~nm}$ was produced at $10 \%$ concentration using 1CMSP:1PEO ratio, which was used for further optimization studies of CMSP/PEO electrospinning.
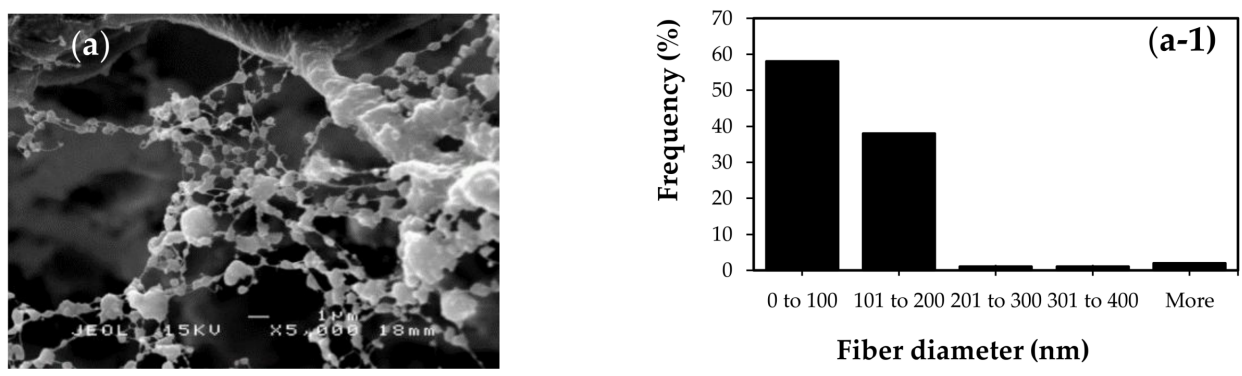

Fiber diameter (nm)
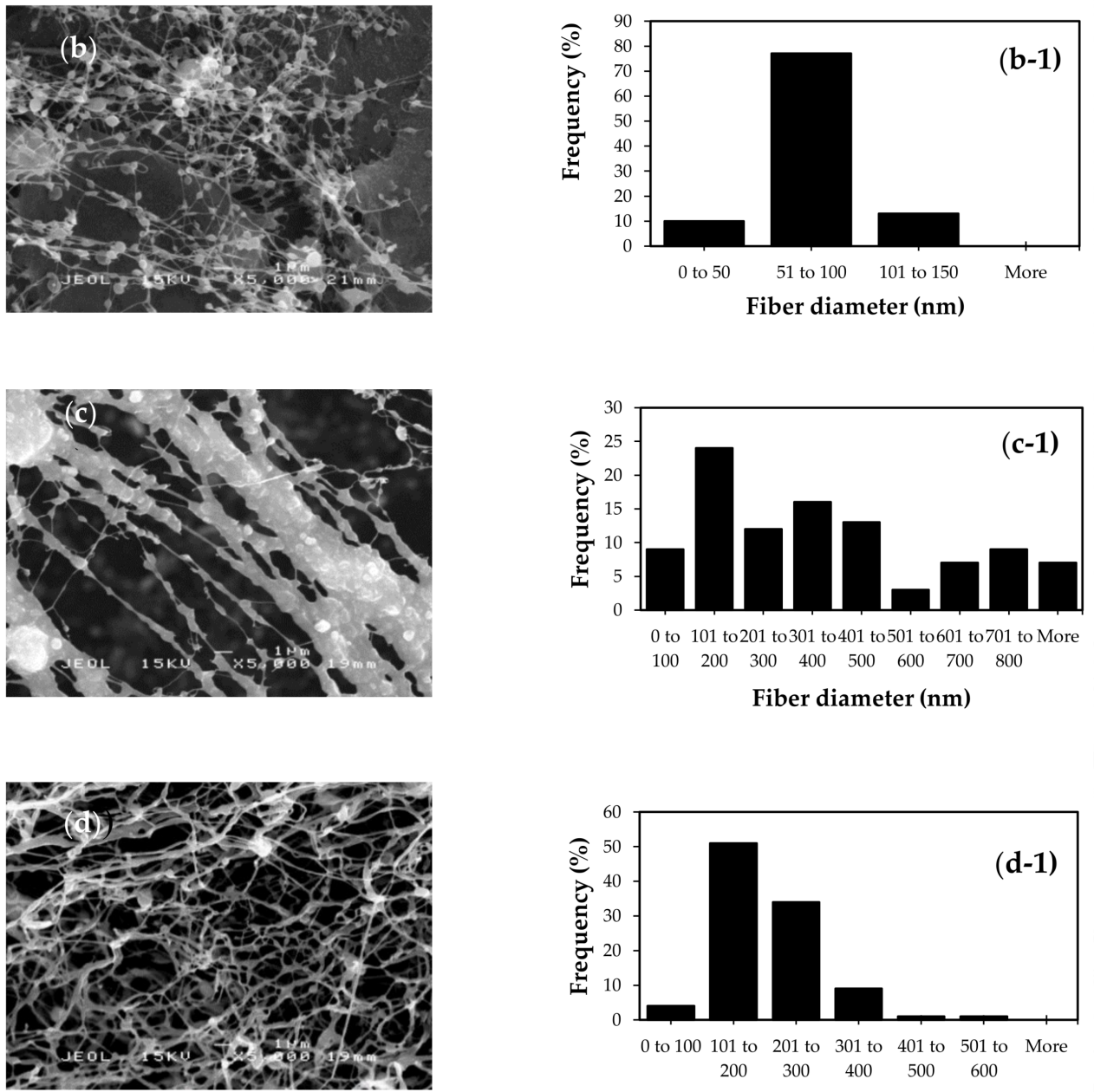

Fiber diameter (nm)
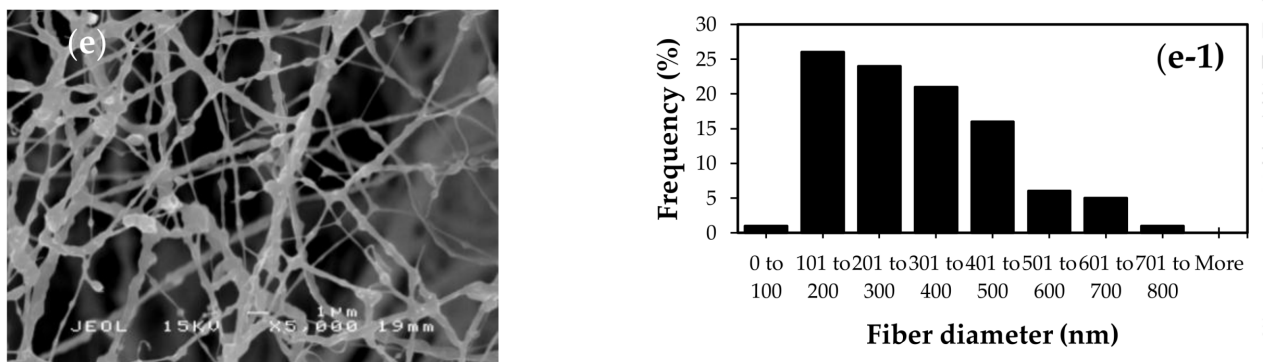

Figure 3. Cont. 

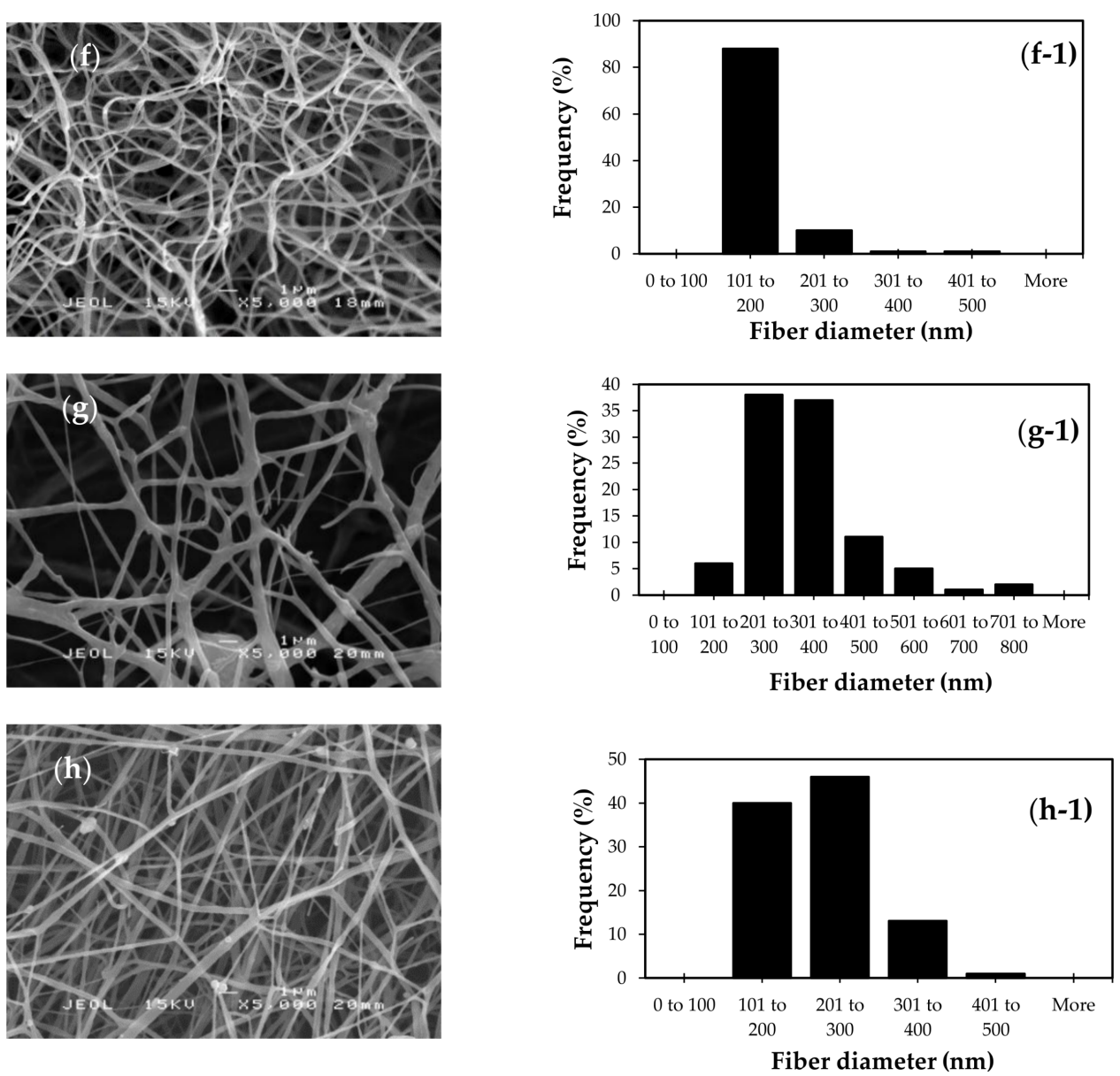

Figure 3. SEM images (a-h) and the corresponding fiber diameter distribution ((a-1)-(h-1)) of CMSP/PEO nanofibers at different concentration of CMSP to PEO solution and ratio of CMSP to PEO (a) $4 \%$ (ratio 1:1), (b) 4\% (ratio 1:3), (c) 6\% (ratio 1:1), (d) 6\% (ratio 1:3), (e) 8\% (ratio 1:1), (f) 8\% (ratio 1:3), (g) 10\% (ratio 1:1) and (h) 10\% (ratio 1:3). Electrospinning parameters were kept constant at $20 \mathrm{kV}$ for applied voltage, $15 \mathrm{~cm}$ of tip-to-collector distance and $0.8 \mathrm{~mL} / \mathrm{h}$ for flow rate.

\subsubsection{Effects of Flow Rate of Syringe Pump}

The influence of flow rate during the electrospinning process was investigated by variation at $0.6,0.8,1.0$, and $1.2 \mathrm{~mL} / \mathrm{h}$ and the resulting nanofibers are shown in Figure 4. Nanofibers with a diameter of $280 \pm 89 \mathrm{~nm}$ were produced at $0.6 \mathrm{~mL} / \mathrm{h}$. When the flow rate was increased to $1.2 \mathrm{~mL} / \mathrm{h}$, the diameter of nanofibers significantly increased with the maximum size of $355 \pm 185 \mathrm{~nm}$ obtained at $1.2 \mathrm{~mL} / \mathrm{h}$ rate. Increasing the flow of solution reduced the time for nanofibers to dry and therefore prompted integration of nanofibers to form a much larger structure [29,41,42]. The nanofibers produced at $0.6 \mathrm{~mL} / \mathrm{h}$ have relatively uniform structures, although the diameter of resulting nanofibers was significantly larger than nanofibers produced at 0.8 and $1.0 \mathrm{~mL} / \mathrm{h}$. Therefore, the flow rate of $0.6 \mathrm{~mL} / \mathrm{h}$ was considered as the optimum rate for fabrication of CMSP nanofibers. For investigating the degree of swelling, the optimized parameters of $10 \%$ solution concentration, 1CMSP:1PEO ratio, $0.6 \mathrm{~mL} / \mathrm{h}$ flow rate, with the constant $20 \mathrm{kV}$ of applied voltage and $15 \mathrm{~cm}$ of tip-to-collector distance, were used to produce hydrogel nanofibers. 

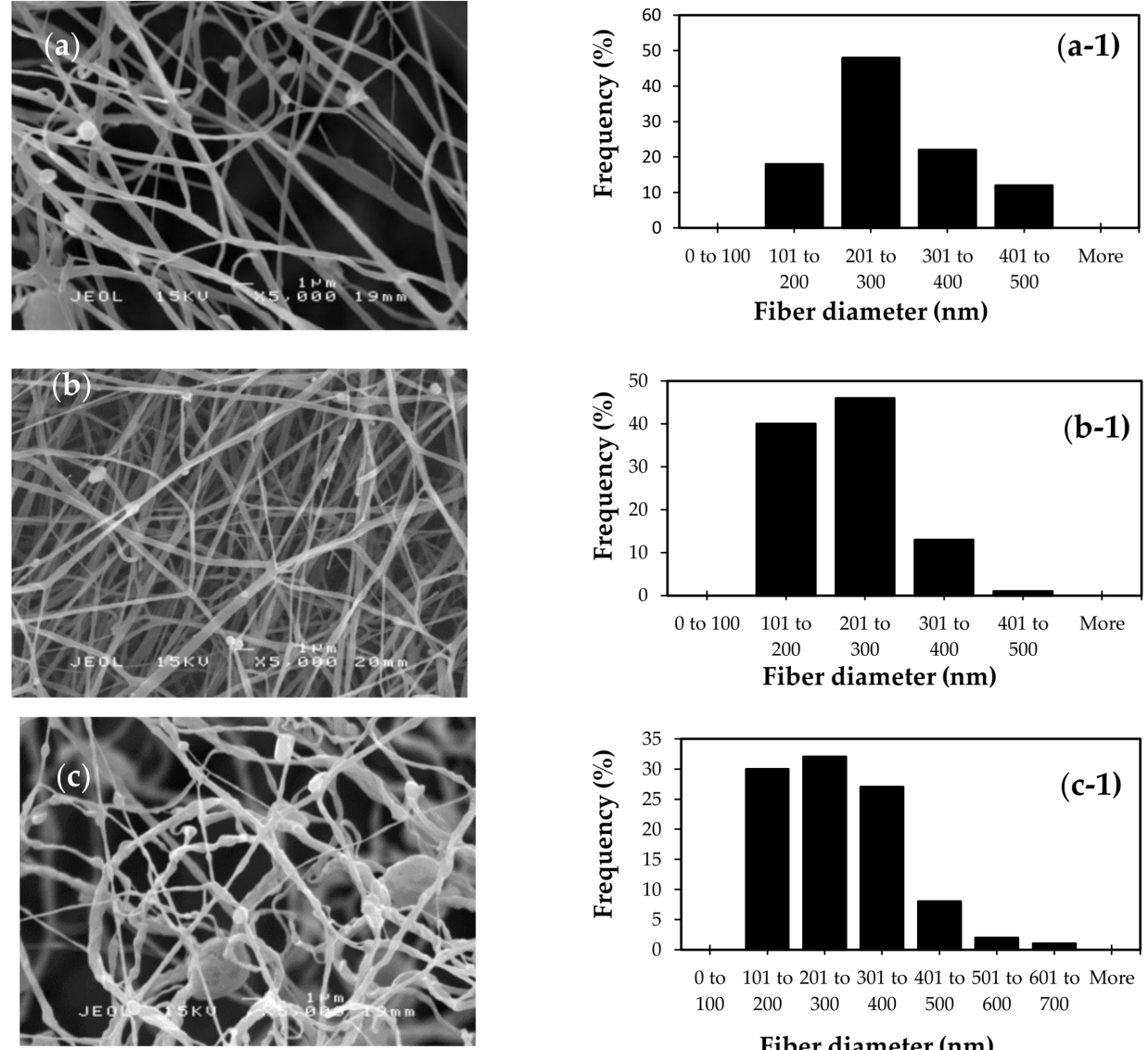

Fiber diameter (nm)
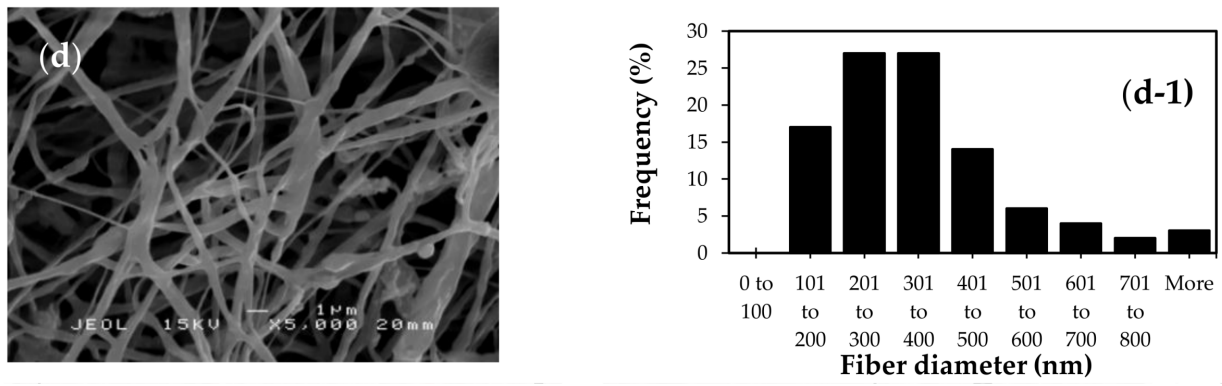

Figure 4. SEM images (a-d) and the corresponding fiber diameter distribution ((a-1)-(d-1)) of CMSP nanofibers produced at flow rate of (a) $0.6 \mathrm{~mL} / \mathrm{h},(\mathbf{b}) 0.8 \mathrm{~mL} / \mathrm{h},(\mathbf{c}) 1.0 \mathrm{~mL} / \mathrm{h}$ and (d) $1.2 \mathrm{~mL} / \mathrm{h}$ at fixed $10 \%$ concentration, 1:1 ratio, $20 \mathrm{kV}$ of applied voltage and $15 \mathrm{~cm}$ tip-to-collector distance.

\subsection{Swelling Studies of CMSP Hydrogel Nanofibers}

Investigation on the swelling percentage of CMSP nanofibers was determined using gravimetric method at a variation of citric acid concentrations and curing temperatures. The duration of curing was kept at $450 \mathrm{~min}$. The percentage of swelling will determine the amount of fluid that can penetrate into the polymeric network, which provides an understanding on the amount of drugs that can retained within the nanofibers structure [43].

\subsubsection{Effects of Percentage of Citric Acid}

Figure 5a shows the relationship between the percentages of swelling upon increasing the concentrations of citric acid. At $23 \%$ of citric acid concentration, the percentage of swelling showed a maximum value of $10,029 \pm 449 \%$. However, the percentage of swelling has significantly reduced to $1491 \pm 126 \%$ at $29 \%$ of citric acid concentration. Although the nanofibers showed high percentage of swelling at $23 \%$ of citric acid concentration, the hydrogel nanofibers were partially dissolved after 
$24 \mathrm{~h}$. Citric acid is a cross-linker that bridges two polymeric chains to form a network that will hold water without initiating dissolution. Figure 6 shows the schematic diagram of a cross-linking reaction between hydroxyl groups from CMSP and citric acid molecules. Here, CMSP plays a dominant role in the cross-linking process compared to PEO. PEO has a long linear chain, has only one hydroxyl group at each end of the chain, while CMSP has much more hydroxyl groups. Low concentrations of citric acid produced a small amount of cross-linked networks relative to the amount of hydroxyl groups available for the interaction with water in the hydrogel. In the presence of a large volume of water, the cross-linked network collapsed and consequently increased the dissolution in water. This occurred for hydrogel nanofibers with $23 \%$ of citric acid, but not at the higher percentage of citric acid. Moreover, the reason why $23 \%$ was chosen as the starting point is because of low percentages lead to total dissolution of hydrogel nanofibers in water. The percentage of swelling for hydrogel nanofibers was decreased when the concentration of citric acid increased to $29 \%$. At high concentrations of citric acid, a high percentage of cross-linked polymeric networks was produced, which significantly improved the ability to retain water molecules in the structure. However, a high percentage of cross-linking also reduced the amount of free hydroxyl groups in the structure, therefore limiting the amount of water that can be accommodated within the network $[7,44,45]$.

\subsubsection{Effects of Curing Temperatures}

Curing is a process where the nanofibers are treated in an oven at certain periods of time for a cross-linking reaction to occur. The percentage of swelling was further investigated by increasing the curing temperatures of the hydrogel nanofibers at $60{ }^{\circ} \mathrm{C}, 70{ }^{\circ} \mathrm{C}, 80^{\circ} \mathrm{C}$ and $90^{\circ} \mathrm{C}$. The results in Figure $5 \mathrm{~b}$ show the highest percentage of swelling at $4366 \pm 975 \%$ when curing temperatures was at $80^{\circ} \mathrm{C}$. Increasing the temperature from $60^{\circ} \mathrm{C}$ to $80^{\circ} \mathrm{C}$ gradually improved the percentage of swelling due to the increment of the cross-linked network within the structure. When temperature increased for a constant time duration, the molecules of CMSP, PEO and citric acid moved quicker, while the energy of the molecules increased. This led to a greater frequency of successful collisions between reactant molecules and the greater the rate of a cross-linking reaction. However at $90{ }^{\circ} \mathrm{C}$, the percentage of swelling was slightly decreased, suggesting a large amount of cross-linking between the polymers produced and caused a rigid cross-linked network. Optimization of the amount of citric acid and the curing temperature on the degree of swelling provides an insight into the ability of hydrogel to adsorb and hold methylene blue within the polymeric network. The optimum CMSP/PEO hydrogel nanofibers $\left(10 \%\right.$ concentration, $1: 1$ ratio, $29 \%$ of citric acid, $80^{\circ} \mathrm{C}$ of curing temperature and $450 \mathrm{~min}$ of curing time) was prepared to proceed with the drug release study.

In this swelling study, a traditional and widely used method of measuring the percentage of swelling is based on the weight of the hydrogel. Inaccuracy of measuring the percentage of swelling may occur due to difficulty in handling swelling hydrogel nanofibers as they have a delicate structure. Structural destruction of hydrogel might occur during weight measurement because swelling of hydrogel nanofibers having low mechanical properties. Extra precaution was taken in this study to ensure accurate result. Recently, a new and more efficient method had been found by Tavakoli et al. (2019) to overcome all the limitations and errors in traditional methods which is known as the fluorescence intensity method (FL). This new method can be employed for obtaining accurate measurements of percentage of swelling hydrogels, especially delicate nanofibers [46]. 

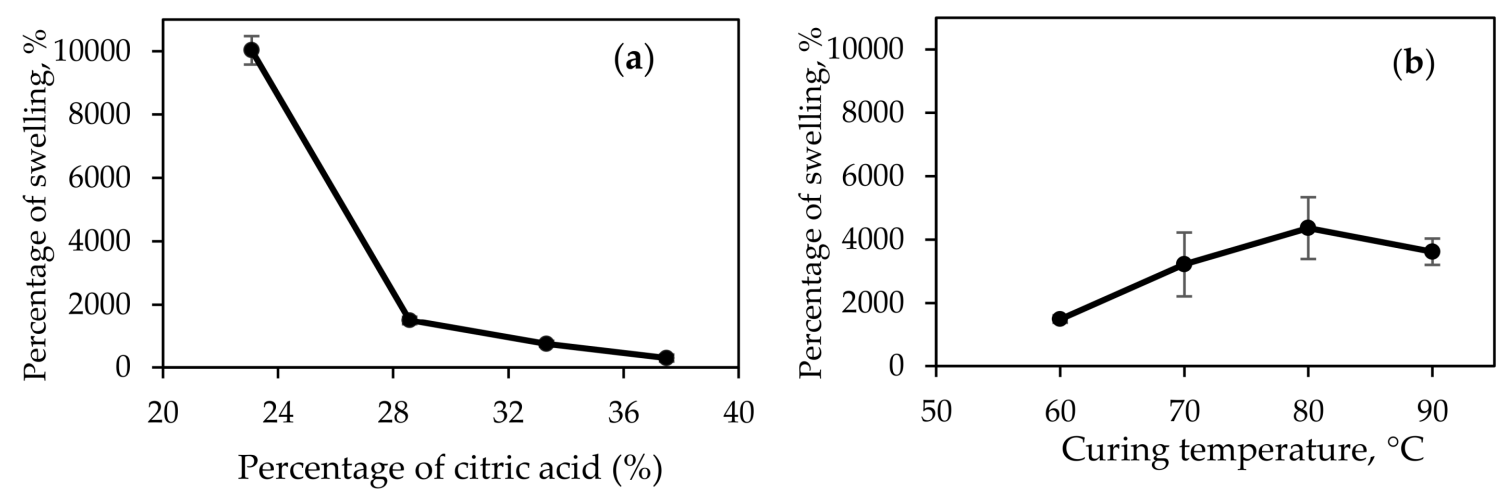

Figure 5. Plot of percentage of swelling at (a) different percentage of citric acid $(23 \%, 29 \%, 33 \%$ and $38 \%$ ) at fixed $60{ }^{\circ} \mathrm{C}$ and $450 \mathrm{~min}$ of curing; and (b) different curing temperature $\left(60{ }^{\circ} \mathrm{C}, 70{ }^{\circ} \mathrm{C}, 80^{\circ} \mathrm{C}\right.$ and $90{ }^{\circ} \mathrm{C}$ ) but at fixed $29 \%$ citric acid, $450 \mathrm{~min}$ of curing.

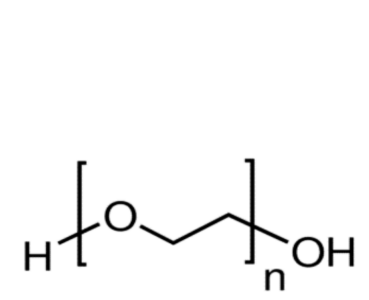

(a)

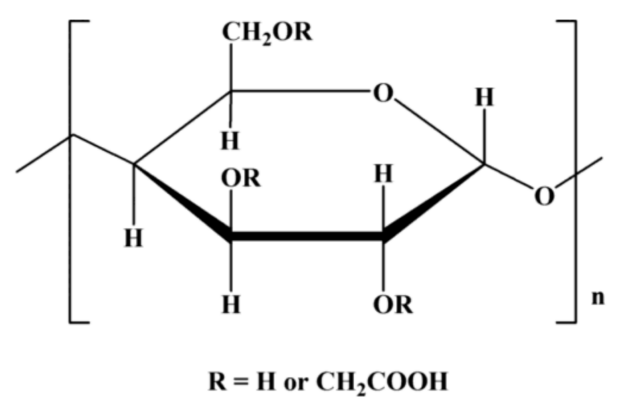

(b)<smiles>CC(C)(C)OC1CC1</smiles><smiles>O=C(O)CC(O)(CC(=O)O)C(=O)O</smiles>

Citric acid<smiles>C[As](C)OPC(=O)CC(O)(CC(=O)OC(C)(C)P)C(=O)O</smiles>

CMSP hydrogel

(c)

Figure 6. (a) PEO structure (b) CMSP structure (c) Proposed mechanism of cross-linking reaction between cellulose (CMSP) and citric acid. 


\subsection{Morphology Studies}

SEM images of the cross-linked CMSP hydrogel nanofibers following immersion in water in swelling studies and adsorption with MB are shown in Figure 7. The morphology of CMSP nanofibers hydrogel was significantly different compared to CMSP nanofibers as shown in Figure 4. The SEM image in Figure 7a shows the CMSP hydrogel nanofibers that were still in nanofibrous form after the cross-linking reaction. This proved that a cross-linking reaction does not affect the morphology of the CMSP nanofibers. The SEM analysis in Figure $7 \mathrm{~b}, \mathrm{c}$ demonstrates swollen nanofibers with the appearance of porous structures. The expansion of the fiber diameter and the formation of porous structures proved that the absorption of water into the hydrogel network produced a high percentage of swelling of the CMSP nanofibers. The nanofibers were cross-linked to form a polymeric network with voids to hold water. The SEM images in Figure 7d,e illustrate the morphology of hydrogel nanofibers following immersion with $\mathrm{MB}$ was different than immersion with water, whereby the nanofibers showed bigger enlargement with less pores and void spaces within the hydrogel network.
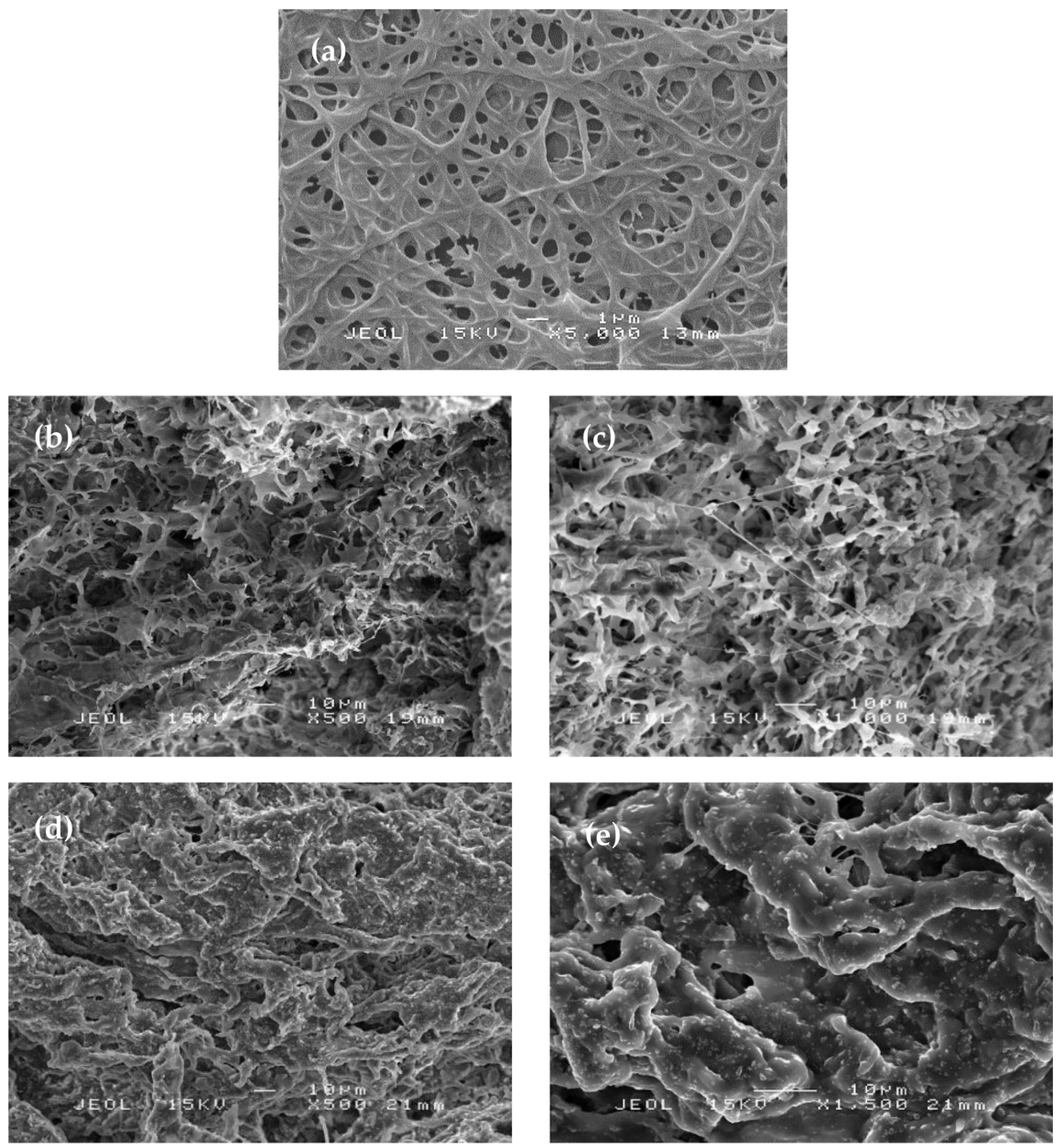

Figure 7. SEM images of (a) cross-linked CMSP hydrogel nanofibers; $(\mathbf{b}, \mathbf{c})$ swollen CMSP hydrogel nanofibers; and (d,e) methylene blue (MB)-loaded CMSP hydrogel nanofibers.

\subsection{Drug Release Studies}

The potential of CMSP hydrogel nanofibers to be used as a drug carrier was investigated on the ability to release the adsorbed $\mathrm{MB}$ at various $\mathrm{pHs}$. Investigations on $\mathrm{pH}$ variation is important to simulate the physiological environments along the human gastrointestinal (GI) tract starting with the saliva at $\mathrm{pH} 5-6$, stomach at $\mathrm{pH} 1-3$, small intestine at $\mathrm{pH}$ 6.6-7.5 and colon at $\mathrm{pH} 6.4-7.0[10,47,48]$. When necessary, the drug release ability at $\mathrm{pH} 7.15-8.9$ is crucial to heal chronic wounds $[10,49]$. 
However, the delicate structure of hydrogel nanofibers may be unsuitable for oral administration. Nevertheless, it can be further applied as wound dressings in wound treatments. Drug release from polymers occurs when a liquid medium penetrates the polymeric network leading to the release of the retained drug by diffusion. Figure 8 shows the MB release profiles from hydrogel nanofibers at different $\mathrm{pH}$ of buffer solutions. In general, the CMSP shows a high degree of MB releases at high $\mathrm{pH}$, with the highest cumulative percentage after $2880 \mathrm{~min}$ obtained at pH 8.0 (21.21\%). Within $30 \mathrm{~min}$ into the investigation, the acceleration of $\mathrm{MB}$ diffusion was observed in all $\mathrm{pH}$ media with similar cumulative percentage releases of $\sim 5 \%$ suggesting the diffusion of MB from CMSP hydrogel nanofibers trapped on the surface of the nanofibers. The initial diffusion of the surface trapped MB also occurred at a similar rate which suggests that the process was not influenced by the $\mathrm{pH}$ of the solution. Monitoring the concentration of $\mathrm{MB}$ after $6 \mathrm{~h}$ showed a rapid diffusion of $\mathrm{MB}$ when the $\mathrm{pH}$ of buffer solution was 7.34, and the rates were slowly reduced as the $\mathrm{pH}$ decreases to 1.2. At $\mathrm{pH} 1.2$, the degree of drug release achieved a steady state at $6 \mathrm{~h}$, with only $9 \%$ of MB detected after $2880 \mathrm{~min}$.

The diffusion of $\mathrm{MB}$ from the hydrogel network was influenced by the $\mathrm{pH}$ of the surrounding medium as $\mathrm{MB}$ is a cationic type drug. At low $\mathrm{pH}$, where high level of proton concentration is available, an equilibrium state between $\mathrm{MB}$ and protonated water occurred, which reduced the diffusion of $\mathrm{MB}$. Increasing the $\mathrm{pH}$ of the buffer solution created osmotic pressure in the surroundings that subsequently increased the diffusion of $\mathrm{MB}$ from the hydrogel network through the channels and pores of nanofibers. A low cumulative percentage release of $\mathrm{MB}$ in all $\mathrm{pHs}$ of the buffer solutions that are less than $22 \%$ indicates the potential use of hydrogel derived from sago pulp waste to prolong the MB retaining time and reduce the dosing frequency of MB. This study suggests that the controlled released of MB from hydrogels is also associated with the presence of cross-linkages between the nanofibers polymers, thus restricting the diffusion rate of $\mathrm{MB}$ into the surrounding medium.

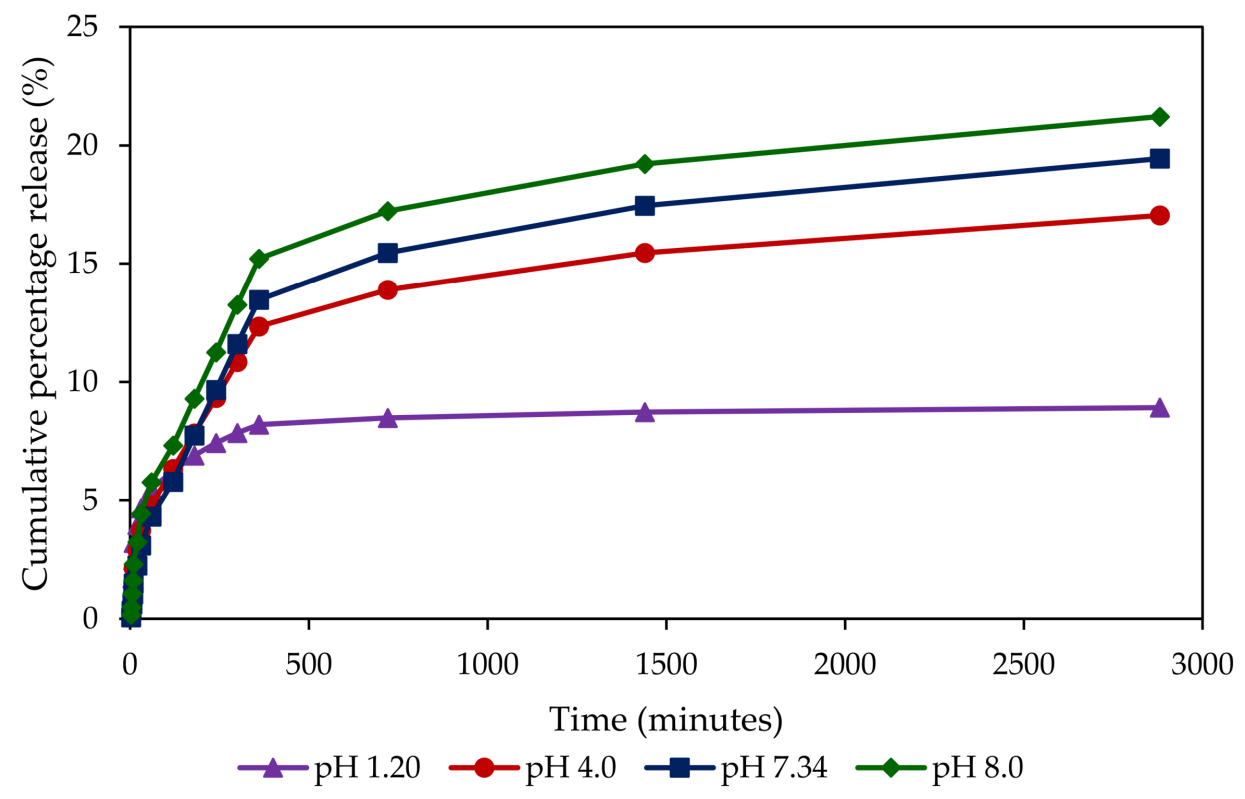

Figure 8. Effects of $\mathrm{pH}$ value on the release of MB from CMSP hydrogel nanofibers.

\section{Conclusions}

This study has investigated the modification of cellulose obtained from sago waste in forming hydrogel nanofibers as a potential drug carrier in wound treatments. The CMSP nanofibers were produced using the electrospinning method with the addition of $\mathrm{PEO}$, which increased the structure and morphology of the nanofibers. The concentration of CMSP/PEO solution, the ratio between CMSP and $\mathrm{PEO}$, and the flow rate of CMSP/PEO during electrospinning, significantly influenced the morphology and size of the nanofibers. An investigation on the percentage of swelling showed that the presence of 
citric acid and the variation of curing temperatures increased the number of cross-linked networks between the nanofibers to form strong polymeric structures responsible for the swelling process. Drug release studies using $\mathrm{MB}$ as a probe molecule showed that hydrogel nanofibers obtained from CMSP has a loading efficiency of $89.20 \pm 0.42 \%$. Drug release profiles of MB-loaded hydrogel nanofibers were significantly influenced by the $\mathrm{pH}$ of buffer solutions and revealed slow release in all $\mathrm{pHs}$, which perhaps demonstrate the potential use of CMSP hydrogel nanofibers as an in vivo or in vitro drug carrier. This preliminary work has illustrated the potential of CMSP nanofibers as a drug carrier that is not only limited to the incorporation of $\mathrm{MB}$, but also applicable for any of hydrophilic pharmaceutical drugs. Due to the delicate nature of hydrogel nanofibers structure, CMSP/PEO hydrogel nanofibers are more suitable for applications, like wound dressing rather than oral administration.

Author Contributions: The work presented in this paper was a collaboration of all authors. The work contribution among the authors as follow: conceptualization, N.A.R.; methodology, N.M.K. and N.H.R.; software, N.M.K.; validation, N.A.R. and N.M.K., and N.A.R.; formal analysis, N.M.K.; investigation, N.M.K.; resources, N.M.K.; data curation, N.M.K.; writing-original draft preparation, N.M.K.; writing-review and editing, H.B. and H.M.; visualization, N.M.K.; supervision, N.A.R.; project administration, N.A.R.; funding acquisition, N.A.R.

Funding: This research was funded by Universiti Putra Malaysia, grant number GP-IPS/2016/9594900 and Graduate Research Fund (GRF) for Nafeesa Mohd Kanafi scholarship. Check carefully that the details given are accurate and use the standard spelling of funding agency names at https://search.crossref.org/funding, any errors may affect your future funding.

Acknowledgments: Authors would like to acknowledge Universiti Putra Malaysia for financial supports through Research University Grant (Grant code: GP-IPS/2016/9594900). Authors would also acknowledge Graduate Research Fund (GRF) for Nafeesa Mohd Kanafi from Universiti Putra Malaysia.

Conflicts of Interest: The authors declare no conflicts of interest.

\section{References}

1. Bujang, K.B.; Hassan, M.A. Recovery of Glucose from Residual Starch of Sago Hampas for Bioethanol Production. Biomed. Res. Int. 2013, 2013, 1-8.

2. Pushpamalar, V.; Langford, S.J.; Ahmad, M.; Lim, Y.Y. Optimization of reaction conditions for preparing carboxymethyl cellulose from sago waste. Carbohydr. Polym. 2006, 64, 312-318. [CrossRef]

3. Deparment of Agriculture Sarawak. Available online: https://www.doa.sarawak.gov.my (accessed on 30 July 2018).

4. Veeramachineni, A.K.; Sathasivam, T.; Muniyandy, S. Optimizing Extraction of Cellulose and Synthesizing Pharmaceutical Grade Carboxymethyl Sago Cellulose from Malaysian Sago Pulp. Appl. Sci. 2016, 6, 170. [CrossRef]

5. Frenot, A.; Henriksson, M.W.; Walkenstro, P. Electrospinning of Cellulose-Based Nanofibers. J. Appl. Polym. Sci. 2007, 103, 1473-1482. [CrossRef]

6. Kanafi, N.M.; Rahman, N.A.; Rosdi, N.H. Citric acid cross-linking of highly porous carboxymethyl cellulose/poly (ethylene oxide) composite hydrogel films for controlled release applications. Mater Today Proc. 2019, 7, 721-731. [CrossRef]

7. Shen, X.; Shamshina, J.L.; Berton, P.; Rogers, R.D. Hydrogels based on cellulose and chitin: Fabrication, properties and applications. Green Chem. 2015, 18, 53-75. [CrossRef]

8. Tan, H.L.; Wong, Y.Y.; Muniyandy, S.; Hashim, K. Carboxymethyl sago pulp/carboxymethyl sago starch hydrogel: Effect of polymer mixing ratio and study of controlled drug release. J. Appl. Polym. Sci. 2016, 43652, 1-13. [CrossRef]

9. Barbucci, R.; Magnani, A.; Consumi, M. Swelling Behavior of Carboxymethylcellulose Hydrogels in Relation to Cross-Linking pH and Charge Density. Macromolecules 2000, 33, 7475-7480. [CrossRef]

10. Rizwan, M.; Yahya, R.; Hassan, A.; Yar, M.; Azzahari, A.; Selvanathan, V.; Sonsudin, F.; Abouloula, C. pH sensitive hydrogels in drug delivery: Brief history, properties, swelling, and release mechanism, material selection and applications. Polymers 2017, 9, 137. [CrossRef]

11. Abrigo, M.; Mcarthur, S.L.; Kingshott, P. Electrospun Nanofibers as Dressings for Chronic Wound Care: Advances, Challenges, and Future Prospects. Macromol. Biosci. 2014, 14, 772-792. [CrossRef] 
12. Tavakoli, J.; Mirzaei, S.; Tang, Y. Cost-effective double-layer hydrogel composites for wound dressing applications. Polymers 2018, 10, 305. [CrossRef] [PubMed]

13. Raucci, M.G.; Demitri, C.; Giugliano, D.; Benedictis, V.; de Sannino, A.; Ambrosio, L. Effect of citric acid crosslinking cellulose-based hydrogels on osteogenic differentiation. J. Biomed. Mater. Res. 2014, 103A, 2045-2056. [CrossRef] [PubMed]

14. Arslan, N. Production of carboxymethyl cellulose from sugar beet pulp cellulose and rheological behaviour of carboxymethyl cellulose. Carbohydr. Polym. 2003, 54, 73-82.

15. Biswas, A.; Kim, S.; Selling, G.W.; Cheng, H.N. Conversion of agricultural residues to carboxymethylcellulose and carboxymethylcellulose acetate. Ind. Crop. Prod. 2014, 60, 259-265. [CrossRef]

16. Bono, A.; Ying, P.H.; Yan, F.Y.; Muei, C.L.; Sarbatly, R.; Krishnaiah, D. Synthesis and Characterization of Carboxymethyl Cellulose from Palm Kernel Cake. Adv. Nat. Appl. Sci. 2009, 3, 5-11.

17. Rachtanapun, P.; Luangkamin, S.; Tanprasert, K.; Suriyatem, R. Carboxymethyl cellulose fi $1 \mathrm{~m}$ from durian rind. YFSTL 2012, 48, 52-58.

18. Pushpamalar, V.; Langford, S.J.; Ahmad, M.; Hashim, K. Preparation of Carboxymethyl Sago Pulp Hydrogel from Sago Waste by Electron Beam Irradiation and Swelling Behavior in Water and Various pH Media. J. Appl. Polym. 2013, 128, 451-459. [CrossRef]

19. Lyn, Y.; Muniyandy, S.; Kamaruddin, H.; Mansor, A.; Janarthanan, P. Radiation cross-linked carboxymethyl sago pulp hydrogels loaded with ciprofloxacin: Influence of irradiation on gel fraction, entrapped drug and in vitro release. Radiat. Phys. Chem. 2015, 106, 213-222.

20. Thenapakiam, S.; Kumar, D.G.; Pushpamalar, J.; Saravanan, M. Aluminium and radiation cross-linked carboxymethyl sago pulp beads for colon targeted delivery. Carbohydr. Polym. 2013, 94, 356-363. [CrossRef]

21. Rathinamoorthy, R.; Technology, F.; College, P.S.G. Nanofiber for drug delivery system. Pak Text J. 2012, 61, 45-48.

22. Haider, A.; Haider, S.; Kang, I. A comprehensive review summarizing the effect of electrospinning parameters and potential applications of nanofibers in biomedical and biotechnology. Arab. J. Chem. 2015, 11, 015. [CrossRef]

23. Teck, C. Progress in Polymer Science Nanofiber technology: Current status and emerging developments. Prog. Polym. Sci. 2017, 70, 1-17.

24. Samadian, H.; Salehi, M.; Farzamfar, S.; Vaez, A.; Ehterami, A.; Sahrapeyma, H.; Goodarzi, A.; Ghorbani, S. In vitro and in vivo evaluation of electrospun cellulose acetate/gelatin/hydroxyapatite nanocomposite mats for wound dressing applications. Artif. Cells Nanomed. Biotechnol. 2018, 46, 964-974. [CrossRef] [PubMed]

25. Basu, P.; Repanas, A.; Glasmacher, B.; Narendrakumar, U.; Manjubala, I. PEO-CMC blend nanofibers fabrication by electrospinning for soft tissue engineering applications. Mater. Lett. 2017, 195, 10-13. [CrossRef]

26. Schirmer, R.H.; Coulibaly, B.; Stich, A.; Scheiwein, M.; Merkle, H.; Eubel, J.; Becker, H.; Muller, O.; Zich, T.; Schiek, W. Methylene blue as an antimalarial agent. Redox Rep. 2003, 8, 272-275. [CrossRef] [PubMed]

27. Oz, M.; Lorke, D.E.; Petroianu, G.A. Methylene blue and Alzheimer's disease. Biochem. Pharmacol. 2009, 78, 927-932. [CrossRef] [PubMed]

28. Wendel, W.B. The control of methemoglobinemia with methylene blue. J. Clin. Investig. 1939, 18, $179-185$. [CrossRef] [PubMed]

29. Pillay, V.; Dott, C.; Choonara, Y.E.; Tyagi, C.; Tomar, L.; Kumar, P.; Ndesendo, V. MA Review of the Effect of Processing Variables on the Fabrication of Electrospun Nanofibers for Drug Delivery Applications. J. Nanomat. 2013, 2013, 1-22. [CrossRef]

30. Dahlan, N.A.; Ng, S.L.; Pushpamalar, J. Adsorption of methylene blue onto powdered activated carbon immobilized in a carboxymethyl sago pulp hydrogel. J. Appl. Polym. Sci. 2017, 134. [CrossRef]

31. Giani, G.; Fredi, S.; Barbucci, R. Hybrid magnetic hydrogel: A potential system for controlled drug delivery by means of alternating magnetic fields. Polymers 2012, 4, 1157-1169. [CrossRef]

32. Foroutan, H.; Khodabakhsh, M.; Rabbani, M. Investigation of synthesis of PVP hydrogel by irradiation. Iran J. Radiat. Res. 2007, 5, 131-136.

33. Huang, W.F.; Tsui, G.C.P.; Tang, C.Y.; Yang, M. Optimization Strategy for Encapsulation Efficiency and Size of Drug Loaded Silica Xerogel/Polymer Core-Shell Composite Nanoparticles Prepared by Gelation-Emulsion Method. Polym. Eng. Sci. 2017, 58, 742-751. [CrossRef] 
34. Shi, Y.; Wan, A.; Shi, Y.; Zhang, Y.; Chen, Y. Experimental and Mathematical Studies on the Drug Release Properties of Aspirin Loaded Chitosan Nanoparticles. BioMed. Res. Int. 2014, 2014. [CrossRef] [PubMed]

35. Chandrasekaran, A.R.; Jia, C.Y.; Theng, C.S.; Muniandy, T.; Muralidharan, S.; Arumugam, S. Invitro studies and evaluation of metformin marketed tablets-Malaysia. J. Appl. Pharm. Sci. 2011, 1, 214-217.

36. Bolio-López, G.I.; Ross-Alcudia, R.E.; Veleva, L.; Azamar, J.A.; Barrios, G.C.M.; Hernández-Villegas, M.M.; Córdova, S.S. Extraction and Characterization of Cellulose from Agroindustrial Waste of Pineapple (Ananas comosus L. Merrill) Crowns. Chem. Sci. Rev. Lett. 2016, 5, 198-204.

37. Fernandes, J.G.; Correia, D.M.; Botelho, G.; Padrão, J.; Dourado, F. PHB-PEO electrospun fiber membranes containing chlorhexidine for drug delivery applications. Polym. Test. 2014, 34, 64-71. [CrossRef]

38. Greiner, A.; Wendorff, JH. Electrospinning: A Fascinating Method for the Preparation of Ultrathin Fibers. Angew. Chem. Int. Ed. 2007, 46, 5670-5703. [CrossRef] [PubMed]

39. Rogina, A. Applied Surface Science Electrospinning process: Versatile preparation method for biodegradable and natural polymers and biocomposite systems applied in tissue engineering and drug delivery. Appl. Surf. Sci. 2014, 296, 221-230. [CrossRef]

40. Sadat, A.; Hamid, M.; Hajiesmaeilbaigi, F. Effect of electrospinning parameters on morphological properties of PVDF nanofibrous scaffolds. Prog. Biomater. 2017, 6, 113-123.

41. Megelski, S.; Stephens, J.S.; Chase, D.B.; Rabolt, J.F. Micro and Nanostructured Surface Morphology on Electrospun Polymer Fibers. Macromolecules 2002, 35, 8456-8466. [CrossRef]

42. Rodoplu, D.; Mutlu, M. Effects of Electrospinning Setup and Process Parameters on Nanofiber Morphology Intended for the Modification of Quartz Crystal Microbalance Surfaces. J. Eng. Fibers Fabr. 2012, 7, 118-123. [CrossRef]

43. Kumar, S.U.; Matai, I.; Dubey, P.; Bhushan, B.; Sachdev, A. Supporting information Differentially cross-linkable core-shell nanofibers for tunable delivery of anticancer drugs: Synthesis, characterization and its anticancer efficacy. Electron. Suppl. Mat. 2014, 4, 38263-38272.

44. Khan, S.; Ranjha, N.M. Effect of degree of cross-linking on swelling and on drug release of low viscous chitosan/poly(vinyl alcohol) hydrogels. Polym. Bull. 2014, 71, 2133-2158. [CrossRef]

45. Reddy, N. Citric acid cross-linking of starch films. Food Chem. 2010, 118, 702-711. [CrossRef]

46. Tavakoli, J.; Zhang, H.P.; Tang, B.Z.; Tang, Y. Aggregation-induced emission lights up the swelling process: A new technique for swelling characterisation of hydrogels. Mater. Chem. Front. 2019, 3, 664-667. [CrossRef]

47. Bhattarai, N.; Gunn, J.; Zhang, M. Chitosan-based hydrogels for controlled, localized drug delivery. Adv. Drug Deliv. Rev. 2010, 62, 83-99. [CrossRef]

48. George, M.; Abraham, T.E. pH sensitive alginate-guar gum hydrogel for the controlled delivery protein drugs. Int. J. Pharm. 2007, 335, 123-129. [CrossRef]

49. Percival, S.L.; Mccarty, S.; Hunt, J.A.; Woods, E.J. The effects of $\mathrm{pH}$ on wound healing, biofilms and antimicrobial efficacy. Wound Rep. Reg. 2014, 22, 174-186. [CrossRef] 